\title{
SIMULATION OF INTERANNUAL VARIABILITY OF SNOW COVER AT VALDAI (RUSSIA) USING A DISTRIBUTED BIOSPHERE HYDROLOGICAL MODEL WITH IMPROVED SNOW PHYSICS
}

\author{
Maheswor SHRESTHA ${ }^{1}$, Lei WANG ${ }^{2}$ and Toshio KOIKE 3 \\ ${ }^{1}$ Student Member of JSCE, Ph. D. Student, Dept. of Civil Eng., University of Tokyo (Bunkyo-ku, Tokyo 113-8656, \\ Japan) \\ ${ }^{2}$ Member of JSCE, Dr. Eng., Research Associate, Dept. of Civil Eng., University of Tokyo (Bunkyo-ku, Tokyo \\ 113-8656, Japan) \\ ${ }^{3}$ Member of JSCE, Dr. Eng., Professor, Dept. of Civil Eng., University of Tokyo (Bunkyo-ku, Tokyo 113-8656, \\ Japan)
}

\begin{abstract}
The distributed biosphere hydrological model (WEB-DHM) was physically improved in snow physics, by incorporating the 3-layer energy balance based snow module of the Simplified Simple Biosphere 3 (SSiB3) model and albedo module of the Biosphere Atmosphere Transfer Scheme (BATS). The new version of WEB-DHM is referred to as WEB-DHM-S. In this study, the WEB-DHM-S is evaluated at Valdai site (Russia) from 1966 to 1983, to check its performance in simulating the interannual variability of snow cover. Results show that the WEB-DHM-S is capable of reproducing the point-scale interannual variations of snow water equivalent, soil and snow surface temperature well. In addition, the good performance of WEB-DHM-S was further confirmed in simulating soil moisture (top 1 m) and evapotranspiration.
\end{abstract}

Key Words : WEB-DHM-S, energy balance, Valdai, interannual variability, snow water equivalent

\section{INTRODUCTION}

Seasonal snow cover is of great importance in understanding the energy and water balance in cold regions. With its inherent properties such as high albedo and low thermal conductivity, it acts as an insulating body for the exchange of energy fluxes between the atmosphere and the land surface. It has ability to store or release water within the hydrological cycle and hence influences the temporal variability of spring snowmelt runoff.

Many studies have been conducted for better representation of snow physics in several climate and hydrological models ${ }^{1,2,3,4,5,6,7,8,9)}$. Some snow model intercomparison studies have been carried out to address the issues related to the current state of snow modeling process ${ }^{10,11,12)}$. The complexity of existing snowmelt models in atmospheric and hydrologic research community ranges from simple degree day models $^{2)}$ to advanced physically based energy balance based models ${ }^{1,3)}$. Degree day models are the black box models while energy balance based models are physically based. One layered energy balance based snow melt models are extensively used for simplicity but these models can not simulate the complete snow physics and many studies $7,10,13,14)$ concluded that at least three layered energy balance based snowmelt model is needed to simulate the diurnal cycle of snow accumulation and snow melting. Furthermore, study towards simulation of an interannual cycle of snow accumulation and melting process is very important to gain an improved understanding of snow processes and to verify the model physics in snow/soil vegetation atmosphere transfer (SVAT) schemes.

This study attempts to evaluate the performance of three layered energy balance based snow melt model in interannual scale. The model here used is Water and Energy Budget - based Distributed Hydrological Model with improved snow physics $(\text { WEB-DHM-S })^{13)}$, developed by coupling three layered snow physics of Simplified Simple

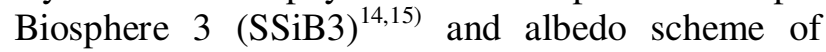


Biosphere Atmosphere Transfer Scheme (BATS) ${ }^{16)}$ into Water and Energy Budget - based Distributed Hydrological Model (WEB-DHM) ${ }^{17,18)}$. The originality of the newly developed model is that it is capable of simulating the snow processes more accurately through the physically based multi layer energy balance modeling approach in the basin scale. However, this study is focused on evaluating the model performance in point scale for the long-term simulation of seasonal and interannual variability of snow cover as long-term high-quality datasets for snow model inputs and evaluations are currently not available over large regions.

\section{STUDY AREA AND DATA}

The study area is the grassland field of Usadievskiy catchment $\left(0.36 \mathrm{~km}^{2}\right)$ in Valdai, Russia $\left(57^{\circ} 58^{\prime} \mathrm{N}, 33^{\circ} 14^{\prime} \mathrm{E}\right) .18$ years of continuous meteorological forcing data $(1966$ - 1983) are used to drive the model. The complete dataset were downloaded from the global moisture data bank ${ }^{19)}$. The atmospheric forcing data includes temperature, pressure, and humidity measured at $2 \mathrm{~m}$ and wind speed at $10 \mathrm{~m}$. These data along with precipitation were originally sampled at 3 -h intervals and were interpolated to 30-min intervals using a cubic-spline interpolation method, but this research used all forcing data at 1-h interval. Downward shortwave radiation and longwave radiation were estimated based on observed cloudiness and temperature ${ }^{20}$. The threshold temperature for snow/rain transition was taken as $0^{\circ} \mathrm{C}^{20)}$.

A continuous snow cover exists from early November to late April. The average annual temperature range is around $35^{\circ} \mathrm{C}$ and temperature falls below $-10^{\circ} \mathrm{C}$ in winter. The soil water is frozen in winter. Average annual precipitation is $730 \mathrm{~mm}$ with the majority falling in summer and autumn months. The annual maximum snow water equivalent (SWE) value ranges from 120 to 170 $\mathrm{mm}$. Evaluation dataset, used in this study, includes SWE, snow and soil surface temperature, total soil moisture in top $1 \mathrm{~m}$ and evapotranspiration (ET). Details of the dataset were given in Schlosser et al. 20). This site was also used in the Project for Intercomparison of Land Surface Schemes (PILPS) - Phase $2(\mathrm{~d})^{10,20)}$ to investigate the snow processes in 21 land surface models.

\section{MODEL}

WEB-DHM-S is the improved version of Water and Energy Budget - based Distributed Hydrological Model (WEB-DHM), with the improvements in the snow physics by coupling three layered energy balance based snowmelt module of SSiB3 and albedo scheme of BATS. WEB-DHM-S can simulate the variability of snow density, snow depth and snow water equivalent, liquid water and ice content, snow albedo, snow layer temperature and thermal heat due to conduction.

In WEB-DHM-S, the snow parameterizations for the canopy are kept the same as in WEB-DHM, but the three layer energy balance based snow scheme is activated when the snow depth is greater than $5 \mathrm{~cm}$. Initially, the snowpack is divided into three layers that start with the same initial snow temperatures. The top layer thickness is kept at a fixed depth of 2 $\mathrm{cm}$ regardless of the total snow depth to provide reasonable simulation of the diurnal changes in the snow surface temperature. The maximum thickness of the middle layer is kept at $20 \mathrm{~cm}$, and the bottom layer represents the remaining body of the snowpack. A surface energy balance equation is formulated only for the top layer, which is influenced by the surface radiation budget and sensible and latent heat fluxes. The heat budget of the second and third layers is controlled by the heat conduction and the penetrating shortwave radiation. And the mass budget for each layer is calculated accordingly by taking account of the precipitation, evaporation, condensation, compaction, liquid water retention, snowmelt runoff and infiltration into the underlying layers. The soil model coupled with a three layer snow model in WEB-DHM-S is shown in Fig. 1.

The equation for enthalpy of each snow layer is $\frac{\partial H\left(Z_{j}\right)}{\partial t}=-\frac{\partial G_{s n}\left(Z_{j}\right)}{\partial Z}$

where $H\left(\mathrm{Jm}^{-3}\right)$ is the volumetric enthalpy of water, $Z_{j}$ is the snow depth of layer $j$ and $G_{s n}\left(\mathrm{Wm}^{-2}\right)$ is the heat flux through the snow layer. $H$ is defined as

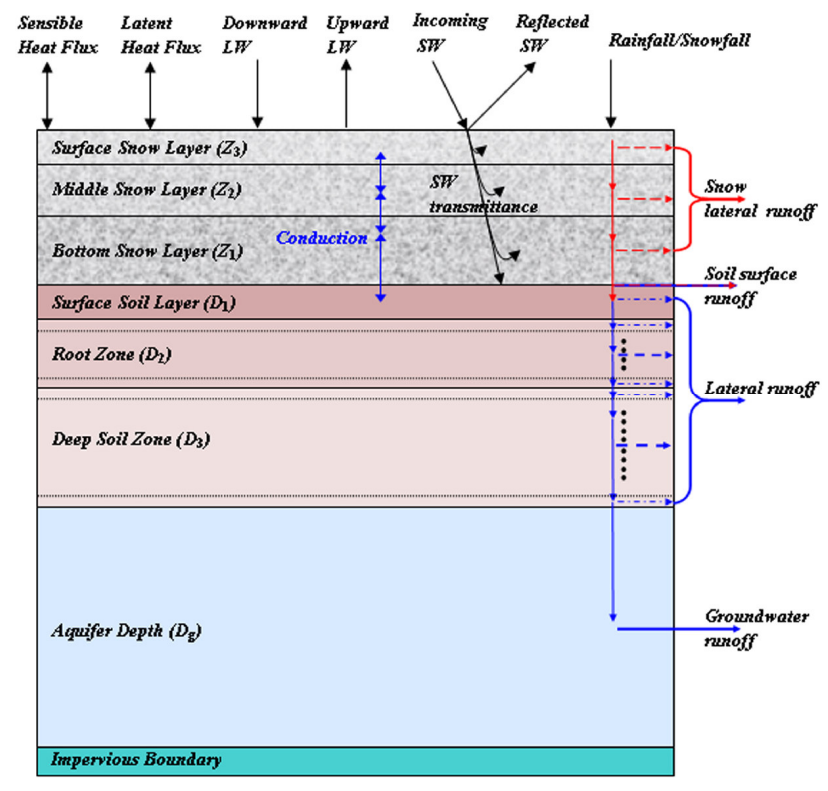

Fig. 1 Coupled soil/snow model in WEB-DHM-S. 


$$
\begin{gathered}
H\left(Z_{j}\right)=C_{v}\left(Z_{j}\right) \times\left\{T_{s n}\left(Z_{j}\right)-273.16\right\}- \\
f_{\text {ice }}\left(Z_{j}\right) \times h_{v} \times \rho_{s}\left(Z_{j}\right)
\end{gathered}
$$

where $C_{v}\left(\mathrm{Jm}^{-3} \mathrm{~K}^{-1}\right)$ and $T_{s n}(\mathrm{~K})$ are mean snow volumetric specific heat capacity and snow temperature respecitively. $C_{v}$ is parameterized as a function of the bulk density of snow and intrinsic density of ice following Verseghy ${ }^{4)}$. $f_{\text {ice }}$ is the dry-snow mass fraction of the total mass in the snow layer, $h_{v}\left(\mathrm{Jkg}^{-1}\right)$ is the latent heat of fusion for ice and $\rho_{s}\left(\mathrm{kgm}^{-3}\right)$ is the bulk density of snow. $G_{s n}$ is defined as

$$
G_{s n}\left(Z_{j}\right)=\left\{\begin{array}{l}
R_{n s n}-H_{s n}-\lambda E_{s n}+G_{p r}, j=3 \\
K\left(Z_{j}\right) \frac{\partial T_{s n}\left(Z_{j}\right)}{\partial Z}+S W_{s n}\left(Z_{j}\right), j=2,1
\end{array}\right.
$$

where $R_{n s n}\left(\mathrm{Wm}^{-2}\right), H_{s n}\left(\mathrm{Wm}^{-2}\right), \lambda E_{s n}\left(\mathrm{Wm}^{-2}\right), G_{p r}$ $\left(\mathrm{Wm}^{-2}\right), K\left(\mathrm{Wm}^{-1} \mathrm{~K}^{-1}\right)$ and $S W_{s n}\left(\mathrm{Wm}^{-2}\right)$ are net radiation, sensible heat, latent heat flux, thermal energy from rain at the snow surface, thermal conductivity of snow and shortwave radiation flux absorbed by the snow layer respectively. The shortwave radiation $S W_{s n}$ at the snow layer is defined following $\operatorname{Jordan}^{3)}$ accounting the penetration of shortwave radiation flux into the snow layers. The process of the calculations of $R_{n s n}$, $H_{s n}$ and $\lambda E_{s n}$ is the same as Sellers et al. ${ }^{21)}$ except that the snow surface temperature is used instead of the average bulk snow temperature for the surface energy balance. The thermal conductivity of snow $K$ $\left(\mathrm{Wm}^{-1} \mathrm{~K}^{-1}\right)$ is calculated from bulk density of ice using the formulations adopted by Jordan ${ }^{3)}$. Thermal energy from rain $\left(G_{p r}\right)$ can be calculated as

$$
G_{p r}=\rho_{w} \times C_{w} \times\left(T_{\text {rain }}-273.16\right) \times I F_{0}
$$

where $I F_{0}\left(\mathrm{~ms}^{-1}\right)$ is the infiltrated flux rate of rain at the snow surface, $T_{\text {rain }}(\mathrm{K})$ is the temperature of rainfall, $\rho_{w}\left(\mathrm{kgm}^{-3}\right)$ and $C_{w}\left(\mathrm{Jkg}^{-1} \mathrm{~K}^{-1}\right)$ are the density and specific heat capacity of water. For simplicity, $T_{\text {rain }}$ is considered as air temperature $\left(T_{\text {air }}\right)$. Ground surface temperature $\left(T_{g}\right)$ and deep soil temperature $\left(T_{d}\right)$ are obtained by considering conductive heat flux at the snow/soil interface and the force-restore model $^{22)}$ of the heat balance in the soil surface.

$$
\begin{aligned}
C_{g} \frac{\partial T_{g}}{\partial t} & =-K\left(Z_{1}\right) \frac{\partial T_{s n}\left(Z_{1}\right)}{\partial Z}-\frac{2 \pi C_{g}\left(T_{g}-T_{d}\right)}{\tau_{d}} \\
C_{d} \frac{\partial T_{d}}{\partial t} & =\frac{2 \pi C_{g}\left(T_{g}-T_{d}\right)}{\tau_{d} \sqrt{365 \pi}}
\end{aligned}
$$

where $C_{g}$ and $C_{d}$ are the effective heat capacity $\left(\mathrm{Jm}^{-2} \mathrm{~K}^{-1}\right)$ for the soil surface and deep soil, $\tau_{d}$ is the day length (s) and $K\left(Z_{1}\right)$ is the effective thermal conductivity at the snow/soil interface. $T_{d}$ is the deep soil temperature.

The mass balance for snow is represented by the change in liquid water and ice content in the snowpack. The relative change in snow mass is controlled by snowfall/rainfall, compaction, snow melting, runoff, infiltration into the underlying snow layer/soil and evaporation/sublimation at the snow surface. The mass balance equations for the snow layer are

$$
\frac{\partial M_{\text {snow }, j}}{\partial t}=\left\{\begin{array}{l}
P_{s}+I F_{0}-I F_{j}-R_{j}-E_{s n}, j=3 \\
I F_{j+1}-I F_{j}-R_{j}, j=2,1
\end{array}\right.
$$

where $M_{\text {snow }, j}(\mathrm{~m})$ corresponds to the SWE at snow layer $j, P_{s}\left(\mathrm{~ms}^{-1}\right)$ is the rate of snowfall, $I F_{j}\left(\mathrm{~ms}^{-1}\right)=$ $\min \left(O_{j}, P_{a v s}\right)$, is the actual liquid water infiltration flux at the interfaces, $R_{j}\left(\mathrm{~ms}^{-1}\right)$ is runoff from the lower interface and $E_{s n}\left(\mathrm{~ms}^{-1}\right)$ is the combined evaporation and sublimation rate. $O_{j}$ is the outflow flux rate which is the liquid water drained to the underlying layer as the total liquid water in layer exceeds its liquid water holding capacity $\left(C_{r}\right)$. Liquid snow mass fraction, $f_{\text {liq }}=\left(1-f_{\text {ice }}\right)$ is used to calculate the total amount of liquid water. $P_{a v s}$ is the pores available in the layer. $R_{j}$ is calculated as the difference between $I F_{j}$ and $O_{j}$. Three snow compaction processes, namely destructive metamorphism, densification due to snow overburden and compaction due to snow melting, are parameterized following Anderson ${ }^{1)}$. Compaction processes are accounted during the calculation of $I F_{j}$. $C_{r}$ is taken as a function of the snow layer density following Anderson ${ }^{1)}$. The bulk density of ice for new snowfall is calculated following the formulation used in the CROCUS snow model ${ }^{5}$ :

$$
\gamma_{i}=109+6 \times\left(T_{a i r}-273.16\right)+26 \times \sqrt{u_{m}}
$$

where $u_{m}$ is the wind speed $\left(\mathrm{ms}^{-1}\right)$. Lower value of density of new snowfall is limited to $50 \mathrm{kgm}^{-3}$.

The snow albedo is parameterized using a physically based prognostic snow albedo scheme of the BATS ${ }^{16)}$ model. The albedo is computed for VIS and NIR spectral bands with adjustments for illumination angle and snow age. The total snow albedo $\left(\alpha_{s}\right)$ is the weighted average of VIS and NIR albedo, which depends on the spectral ratio of the incident shortwave radiation. VIS and NIR albedo $\left(\alpha_{v i s}, \alpha_{n i r}\right)$ are defined as

$$
\begin{aligned}
& \alpha_{\text {vis }}=\alpha_{v d}+0.4 \times f_{\text {zen }} \times\left(1-\alpha_{v d}\right) \\
& \alpha_{\text {nir }}=\alpha_{\text {nird }}+0.4 \times f_{\text {zen }} \times\left(1-\alpha_{\text {nird }}\right) \\
& \alpha_{v d}=\alpha_{v i s 0} \times\left(1-0.2 \times f_{\text {age }}\right) \\
& \alpha_{\text {nird }}=\alpha_{\text {nir } 0} \times\left(1-0.5 \times f_{\text {age }}\right)
\end{aligned}
$$

where $\alpha_{v d}$ and $\alpha_{\text {nird }}$ are the albedo of the diffused shortwave radiation in the VIS and NIR bands respectively, $\alpha_{v i s 0}(0.85)$ and $\alpha_{\text {nir }}(0.65)$ represent fresh-snow albedo for the VIS and NIR bands, $f_{z e n}$ is the correction term for a solar zenith angle larger than $60^{\circ}$ and $f_{\text {age }}$ is the snow aging factor accounting for the effect of grain growth due to vapor diffusion and the effect of dirt and soot. Details of $f_{\text {zen }}$ and $f_{\text {age }}$ 
Table 1 The parameters used in WEB-DHM-S at Valdai.

$\begin{array}{ll}\text { VIS }\left(\alpha_{\text {vis }}\right) \text { \& NIR }\left(\alpha_{\text {nir }}\right) \text { albedo of fresh snow } & 0.85 ; 0.65 \\ \text { VIS \& NIR albedo of soil } & 0.10 ; 0.20 \\ \text { Top soil, root soil and deep soil zone }(\mathrm{m}) & 0.1 ; 0.9 ; 1.0 \\ \text { Vegetation coverage }(\%) & 90.0 \\ \text { Bare soil coverage }(\%) & 10.0 \\ \text { Canopy top height, } z_{2}(\mathrm{~m}) & 0.60 \\ \text { Canopy base height, } z_{I}(\mathrm{~m}) & 0.10 \\ \text { Roughness length of snow }(\mathrm{m}) & 0.0024 \\ \text { Roughness length of soil }(\mathrm{m}) & 0.035 \\ \text { Porosity of soil } & 0.401 \\ \text { Sat. hydraulic conductivity for soil }\left(\mathrm{ms}^{-1}\right) & 0.00002 \\ \text { Sat. hydraulic conductivity for snow }\left(\mathrm{ms}^{-1}\right) & 0.01 \\ \text { Zero plane displacement height }(\mathrm{m}) & 0.25 \\ \text { Threshold temperature to separate rain } / \mathrm{snow}^{\circ}\left({ }^{\circ} \mathrm{C}\right) & 0.0\end{array}$

can be found in Yang et al. ${ }^{16}$. The soil moisture and ET are calculated as $\mathrm{SiB} 2^{21)}$. Model parameters specific to Valdai site are given in Table 1. The model is run from January 1966 to December 1983 with initial conditions of observed soil temperature, soil moisture and SWE. The model performance is evaluated by Mean Bias Error (MBE) and Root Mean Square Error (RMSE), defined as followings;

$$
\begin{aligned}
& M B E=\sum_{i=1}^{n}\left(S_{i}-O_{i}\right) / n \\
& R M S E=\sqrt{\sum_{i=1}^{n}\left(S_{i}-O_{i}\right)^{2} / n}
\end{aligned}
$$

where $n$ is the total number of time series, $S_{i}$ is the simulation result and $O_{i}$ is the observed data.

\section{RESULTS AND DISCUSSIONS}

\section{(1) Snow Water Equivalent (SWE)}

SWE is one of the very important variables in snow hydrology as it is a direct measure of the total liquid water available in the snowpack. Proper simulation of SWE is critical in predicting seasonal discharge. The comparison of SWE simulated by WEB-DHM-S and the observed monthly SWE values are shown in Fig. 2. The observed value represent the catchment averaged SWE based on snow course measurements from 44 individual sites throughout the catchment.

Fig. 2 shows that model is able to simulate long term interannual variability of snow cover well. SWE in $1967 / 68$ and $1968 / 69$ were less simulated following excessive simulation in some other years, similar to the study by Slater et al. ${ }^{10}$. . Over estimation of SWE in some years may be due to specific blowing snow conditions. Model BIAS and RMSE are given in Table 2 and its value averaged over 18 year simulation, are given in Table 3. The model is able to simulate the observed low accumulation year (1971/72) and high accumulation year (1975/76) quite well but it is unable to simulate mid-season ablation in the winters of 1970/71 and 1973/74 (Fig. 2), consistent to the results in PILPS- $2 \mathrm{~d}^{10)}$. We simulated the SWE by changing the threshold temperature to 1 and $2^{\circ} \mathrm{C}$, but the bias in mid-season ablation is not improved (not shown here). The biases for many years may be basically due to the problem with the forcing, such as overcatch.

\section{2) Skin Surface Temperature (SST)}

SST is another important parameter of the land surface energy balance. It directly affects the sensible and latent heat fluxes. It is the key variable for the estimation of upward longwave radiation when the in-situ data are not available. The comparison between observed and simulated daily SST is shown in Fig. 3.

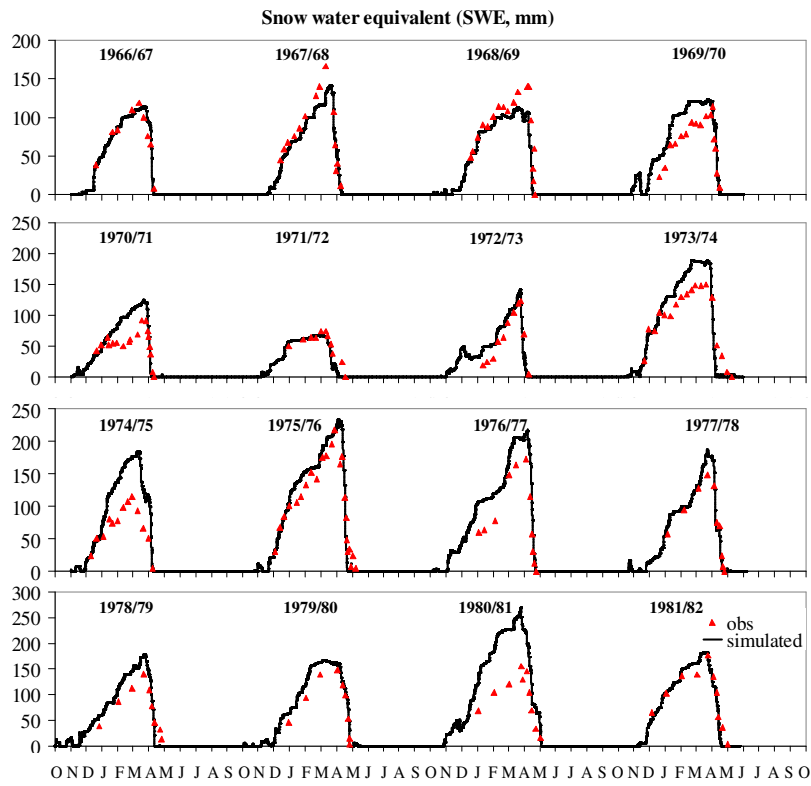

Fig. 2 Observed and simulated snow water equivalent (SWE) from hydrological year $1966 / 67$ to $1981 / 82$

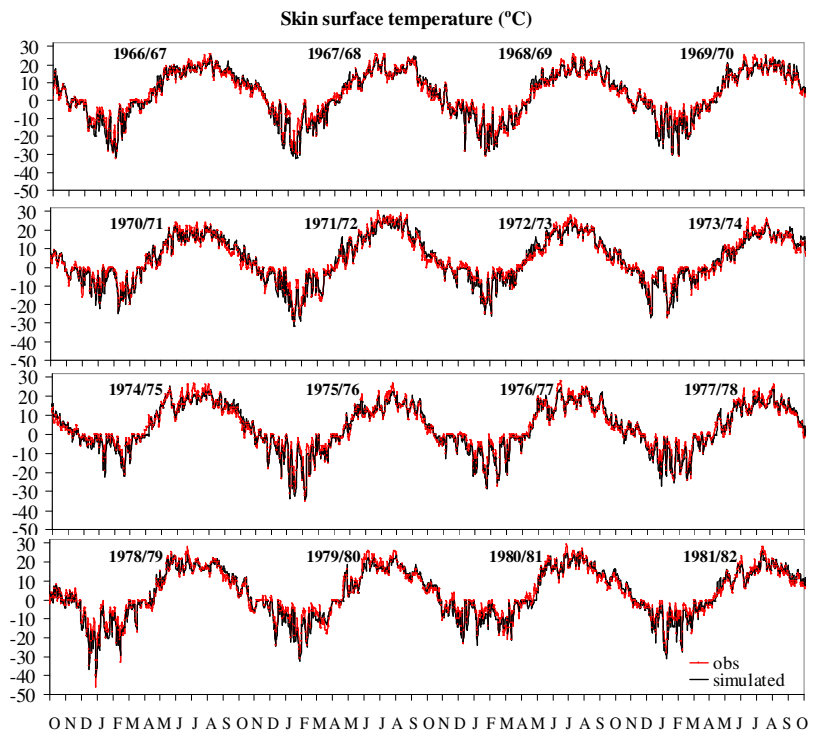

Fig. 3 Observed and simulated skin surface temperature (SST) from hydrological year $1966 / 67$ to $1981 / 82$ 
Table 2 MBE and RMSE for SWE \& SST (1966-1983)

\begin{tabular}{lllll}
\hline \multirow{2}{*}{ Year } & \multicolumn{2}{c}{ SWE $(\mathrm{mm})$} & \multicolumn{2}{c}{ SST $\left({ }^{\circ} \mathrm{C}\right)$} \\
\cline { 2 - 5 } & MBE & RMSE & MBE & RMSE \\
\hline $66 / 67$ & 2.31 & 10.24 & -0.35 & 2.29 \\
$67 / 68$ & -9.18 & 16.81 & -0.52 & 2.42 \\
$68 / 69$ & -20.03 & 26.5 & -0.20 & 2.14 \\
$69 / 70$ & 22.38 & 25.00 & -0.62 & 2.41 \\
$70 / 71$ & 15.73 & 28.69 & -0.29 & 2.00 \\
$71 / 72$ & -8.57 & 14.37 & -0.39 & 2.51 \\
$72 / 73$ & 11.08 & 20.39 & -0.29 & 2.07 \\
$73 / 74$ & 12.19 & 29.58 & -0.43 & 2.17 \\
$74 / 75$ & 44.49 & 52.84 & -0.54 & 2.20 \\
$75 / 76$ & 5.42 & 23.99 & -0.47 & 2.19 \\
$76 / 77$ & 37.98 & 40.01 & -0.66 & 2.06 \\
$77 / 78$ & 2.74 & 14.25 & -0.81 & 2.22 \\
$78 / 79$ & 7.45 & 28.06 & -0.56 & 2.41 \\
$79 / 80$ & 10.21 & 16.10 & -0.72 & 2.67 \\
$80 / 81$ & 63.44 & 71.59 & -0.80 & 2.43 \\
$81 / 82$ & -7.55 & 18.20 & -0.27 & 2.30 \\
$82 / 83$ & 43.57 & 49.48 & 0.10 & 2.12 \\
\hline
\end{tabular}

Table 3 Statistic analysis of model simulation (1966-1983)

\begin{tabular}{lll}
\hline & MBE & RMSE \\
\hline Snow water equivalent $(\mathrm{mm})$ & 12.09 & 31.62 \\
Skin surface temperature $\left({ }^{\circ} \mathrm{C} /\right.$ daily $)$ & -0.48 & 2.29 \\
Soil moisture $(\mathrm{mm} / \mathrm{mon}$ th) & 12.11 & 30.17 \\
Evapotranspiration up to $1973(\mathrm{~mm} /$ month) & -6.09 & 10.86 \\
\hline
\end{tabular}

SST is calculated as the soil surface temperature in the absence of snow cover and as the snow surface temperature in the presence of the snow cover. The observed SST shows strong interannual variation in snow cover season. The overall seasonal and annual cycle of SST are well captured for the almost all months of the simulation years (1966/67-1981/82). This implies that the model is capable of simulating the surface energy budget over the soil and snow surface. MBE and RMSE for SST are given in Table 2 and its value averaged for 18 years are found to be $-0.48^{\circ} \mathrm{C}$ and $2.29^{\circ} \mathrm{C}$ respectively (Table 3 ).

\section{3) Albedo}

Albedo is a measure of fraction of solar radiation that is absorbed by the earth surface. It has significant contribution to the radiation budget during the snow melting period. Hence, the accurate simulation of snow cover period is highly governed by the snow albedo. Fig. 4 shows the interannual variation of albedo values simulated by the model. The simulated daily albedo has a range of 0.2 to 0.8 . As albedo is a function of grain size, age and snow surface temperature, the seasonal and interannual variability of albedo highly depend on the snow depth. The simulated albedo is relatively small in 1971/72 (with the lowest peak of SWE) and relatively big in 1975/76 (with the highest peak of SWE).

\section{4) Soil moisture and ET}

Fig. 5 compares the simulated and observed mean monthly soil moisture in top $1 \mathrm{~m}$. The results show that the model can capture the observed seasonal and interannual variability of soil moisture well in the pattern but accompanied with large bias. However, an increase in soil moisture due to snowmelt infiltration is reasonably simulated. The model is able to simulate relatively dry conditions in 1972 and 1975, although the model overestimated them. The remarkable positive bias may be due to the effect of frozen soil. Overall, MBE (12.11 mm) and RMSE $(30.17 \mathrm{~mm})$ values for monthly soil moisture are obtained for the 18-year simulation (Table 3). The monthly ET simulated by the model is shown in Fig. 6 and compared with the measurements by Fedorov ${ }^{23)}$ up to 1973. The results show that the capability of the model in simulating the seasonal cycle of ET is found quite well. The observed monthly-mean ET ranges from $4.2 \mathrm{~mm}$ in November to $102 \mathrm{~mm}$ in June. The ET during snow cover days is underestimated by the model whereas that in summer is comparable to the observations.

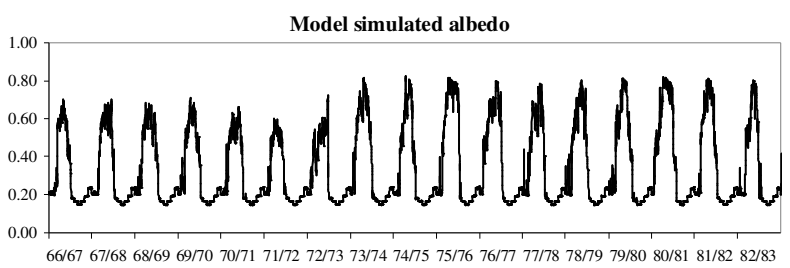

Fig. 4 Model simulated daily averaged albedo from 1966/67 to $1982 / 83$

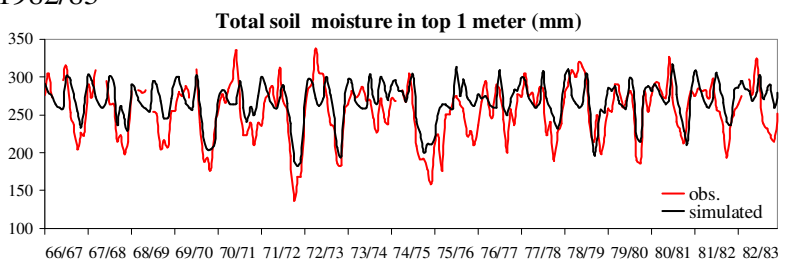

Fig. 5 Observed and simulated mean monthly soil moisture in top one meter soil from $1966 / 67$ to $1982 / 83$

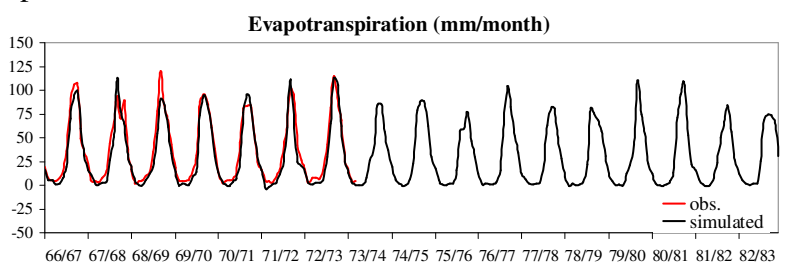

Fig. 6 Observed (up to 1973) and simulated monthly ET from $1966 / 67$ to $1982 / 83$.

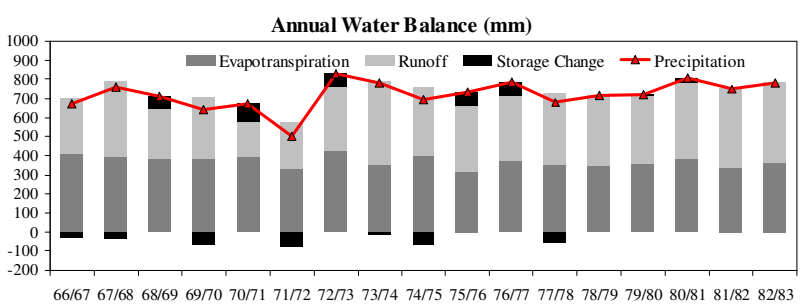

Fig. 7 Annual water balance from 1966/67 to 1982/83.

The annual water balance is shown in Fig. 7. The runoff is computed as the sum of surface runoff and outflow from vertical soil column. Fig. 7 shows that the ET and runoff usually have equal weights to 
the total precipitation. The 18 years averaged ratio of ET to the total precipitation is found to be 0.52 . Remarkable positive storage was observed in the years 68/69, 70/71, 72/73, 75/76, 76/77 whereas negative storage was predominant in the years 69/70, 71/72, 74/75, 77/78, which mostly follows the soil moisture evolution as shown in Fig. 5.

\section{CONCLUSIONS}

In this study, the newly developed energy balance based snow melt model, WEB-DHM-S was evaluated at Valdai site for long term simulation of snow cover from 1966 to 1983 . The model is found to be able to simulate reasonably well the seasonal and interannual variability of observed snow water equivalent (SWE), skin surface temperature (SST), soil moisture in top $1 \mathrm{~m}$ and ET. Model biases in some years may be attributed to the error in forcing data and/or blowing condition of snow. The WEB-DHM-S provides physical details of snow processes, which make it possible to continuously simulate long-term snow hydrology in the basin scale with a distributed manner. Furthermore, blowing snow module and advanced schemes for representation of frozen soil processes will be added to the current model for better representation of snow processes in future.

ACKNOWLEDGMENT: This study was supported by the Japanese Ministry of Education, Science, Support and Culture (MEXT). The authors express deep gratitude to Professor Yongkang Xue, University of California at Los Angeles for providing the codes of $\mathrm{SSiB} 3$ model.

\section{REFERENCES}

1) Anderson, E. A.: A point energy and mass balance model of a snow cover, NOAA Tech. Rep. NWS 19, U.S. Dept. of Commerce, Washington, DC, 150pp., 1976.

2) Martinec, J.: Snowmelt-Runoff Model for stream flow forecasts, Nordic Hydrol., Vol. 6(3), pp.145-154, 1975.

3) Jordan, R.: A one-dimensional temperature model for a snow cover, U.S. Army Corps of Engineers, Cold Regions Research and Engineering Laboratory, Special Report 91-16, 49 pp., 1991

4) Verseghy, D. L.: CLASS - a Canadian land surface scheme for GCMs: I. Soil model, Int. J. Climatol., Vol. 11, pp.111-133, 1991.

5) Brun, E., Martin, E., Simon, V., Gendre, C. and Coleou, C.: An energy and mass model of snow cover suitable for operational avalanche forecasting, J. Glaciol., Vol. 35, pp.333-342, 1989.

6) Tarboton, D. G. and Luce, C. H.: Utah Energy Balance Snow Accumulation and Melt Model (UEB), Computer model technical description and users guide, Utah Water Research Laboratory and USDA Forest Service Intermountain
Research Station, Logan, 63 pp., 1996

7) Sun, S. F., Jin, J. and Xue, Y.: A simple snow-atmosphere-soil transfer model, J. Geophys. Res., Vol. 104(D16), pp.19587-19597, 1999.

8) Zanotti, F., Endrizzi, S., Bertoldi, G. and Rigon R.: The GEOTOP snow module, Hydrol. Process., Vol. 18, pp.3667-3679, 2004.

9) Liston, G. E. and Elder, K: A distributed snow-evolution modeling system (SnowModel), J. Hydrometeorol., Vol. 7, pp.1259-1276, 2006.

10) Slater, A. G., and coauthors: The representation of snow in land surface schemes: Results from PILPS 2(d), $J$. Hydrometeorol., Vol. 2, 7-25, 2001.

11) Etchevers, P., and coauthors: Validation of the energy budget of an alpine snowpack simulated by several snow models (SnowMIP project), Ann. Glaciol., Vol. 38, 150-158, 2004.

12) Rutter, N., and coauthors: Evaluation of forest snow process models (SnowMip2), J. Geophys. Res., Vol. 114(D06111), 2009.

13)Shrestha, M., Wang, L., Koike, T., Xue, Y., and Hirabayashi, Y.: Improving the snow physics of WEB-DHM and its point evaluation at two SnowMIP alpine sites, Hydrol. Earth Syst. Sci. Discuss., Vol. 7, pp.3481-3519, doi:10.5194/hessd-7-3481-2010, 2010.

14) Xue, Y., Sun, S., Kahan, D. S. and Jiao, Y.: Impact of parameterizations in snow physics and interface processes on the simulation of snow cover and runoff at several cold region sites, J. Geophy. Res., Vol. 108(D22), 8859, 2003.

15) Sun, S. and Xue, Y.: Implementing a new snow scheme in Simplified Simple Biosphere Model, Adv. Atmos. Sci., Vol. 18, pp.335-354, 2001.

16) Yang, Z.-L., Dickinsion, R. E., Robock, A. and Vinnikov, K. Y.: Validation of the snow submodel of the Biosphere-Atmosphere Transfer Scheme with Russian snow cover and meteorological observational data, $J$. Climate., Vol. 10, pp.353-373, 1997.

17) Wang, L., Koike, T., Yang, K., Jackson, T., Bindlish, R. and Yang, D.: Development of a distributed biosphere hydrological model and its evaluation with the Southern Great Plains Experiments (SGP97 and SGP99), J. Geophys. Res.-Atmos., Vol. 114, D08107, 2009.

18) Wang, L., Koike, T., Yang, K. and Yeh, P. : Assessment of a distributed biosphere hydrological model against streamflows and MODIS land surface temperature in the upper Tone river basin, J. Hydrol., Vol. 377, pp.21-34, 2009.

19) Robock, A., and coauthors: The Global Soil Moisture Data Bank, Bull. Amer. Meteorol. Soc., Vol. 81, pp.1281-1299, 2000.

20) Schlosser, A., and coauthors: Simulations of a boreal grassland hydrology at Valdai Russia: PILPS Phase 2(d), Mon. Wea. Rev., Vol. 128, pp. 301-321, 2000.

21) Sellers, P. J., and coauthors: A revised land surface parameterization (SiB2) for atmospheric GCMs, Part I: Model Formulation, J. Climate, Vol. 9, pp.676-705, 1996.

22) Deardorff, J. W.: Efficient prediction of ground surface temperature and moisture, with inclusion of a layer of vegetation, J. Geophys. Res., Vol. 83, 1889-1903, 1978.

23) Fedorov, S. F.: A study of the components of the water balance in forest zone of European part of the USSR (in Russian), Gidrometeoizdat, 264 pp., 1977.

(Received September 30, 2010) 